\title{
Gramática Tradicional ou Normativa? Um enredamento de língua, política, educação e ciência
}

\author{
Traditional or normative grammar? A question of \\ language, politics, education and science
}

\author{
André Luiz Ming Garcia \\ Instituto Goethe de São Paulo
}

\section{Resumo}

O objetivo do presente trabalho consiste em discutir, em primeiro lugar, a associação frequente que se estabelece, tanto entre leigos quanto entre alguns gramáticos, entre as noçōes de "Gramática Tradicional" (GT) e "gramática normativa" ou "prescritiva". Para tal, analisam-se os conceitos de tradição e norma. Em segundo plano discutem-se, ainda, juízos de valor comumente atribuídos a GT e o seu papel no ensino comunicativo de línguas estrangeiras, a exemplo do alemão, em constante diálogo com outras teorias e modelos, a ser didatizados pelo professor crítico. Conclui-se que a GT consiste num modelo teórico descritivo do sistema de regras inerente à língua com base em perspectivas específicas, assim como o são os demais, com suas limitações e vantagens, e que o caráter prescritivo ou normativo que lhe é atribuído deriva de açōes extralinguísticas, de cunho político e ideológico, não sendo necessariamente intrínsecas ao modelo em si. Discute-se, à guisa de exemplo, a ampla aplicação de termos e conceitos oriundos da GT em livros didáticos comunicativos de línguas estrangeiras, de modo a aproveitar em sala de aula os pré-conhecimentos metalinguísticos de base dos discentes, adquiridos durante a aprendizagem da norma culta da língua materna, no período escolar. 


\section{Palavras-chave}

Gramática Tradicional, Gramática normativa, Ensino de línguas, Linguística Aplicada.

\section{Abstract}

The purpose of this paper is to focus on the frequent association that is established, both among laymen and among some grammarians, between the notions of "Traditional Grammar" (TG) and "normative" or "prescriptive grammar". To this end, we analyze the concepts of tradition and norm. In the background, values commonly attributed to TG and its role in commiunicative teaching of foreign languages are discussed, such as the case of German, in constant dialogue with other thories and models to be worked upon by the teacher. It is concluded that the TG model is a theoretical description of the system of rules that are inherent in the language from a specific perspective, with its limitations and advantages, and that the prescriptive or normative character assigned to it derives from extra-linguistic actions, a political and ideological motivation, not necessarily intrinsic to the model itself. It discusses the wide application of terms and concepts from TG in textbooks of communicative foreign language teaching in order to take advantage of the pre-metalinguistic knowledge base of learners, acquired during the learning of the mother tongue at school.

\section{Keywords}

Traditional Grammar, Grammar rules, Language teaching, Applied Linguistic. 


\section{Introdução}

"It may also be pointed out here that what is generally referred to as 'traditional grammar' (and we shall continue to use this term) is much richer and more diversified than is often suggested in the cursory references made to it by many modern handbooks of linguistics. Much of the earlier history of Western linguistic though is obscure and controversial. This is mainly due to the fact that most of the original sources have disappeared: from what has survived it is clear that, although one can trace a continuous line of development from Plato and the Sophists to the medieval Schoolmen, throughout this period there were many individual grammarians who were capable of original thought. A definitive and comprehensive history of 'traditional grammar' is yet to be written.” (LYONS, 1968, p. 3)

"El objeto de la gramática, cualesquiera que sean sus fundamentos teóricos, es descubrir la razón por la cual un enunciado lineal es más que una agrupación accidental.” (DELGADO LEÓN, 1977, p. 86)

$\mathrm{U}$ $\mathrm{m}$ breve estudo do percurso do desenvolvimento da atividade metalinguística no Ocidente é capaz, por si só, de demonstrar razoavelmente quais foram as principais noçōes acerca do fenômeno humano da linguagem surgidas desde a Grécia antiga. Noçóes essas que emergiram, a priori, no seio de estudos de cunho lógico e filosófico que, eventualmente, vieram a se desdobrar, como berços avant la lettre de áreas autônomas de estudos a que deram origem, tais como a Semiótica, a Linguística e, dentro desta, as Gramáticas Descritivas ou Científicas. Na eventual ausência de interesse no empreendimento de tal estudo, bastaria uma mera observação atenta das práticas escolares contemporâneas no âmbito do ensino de línguas maternas e estrangeiras para que se reconhecessem, nítidos e vivos, indícios nada sub-reptícios da presença ininterrupta de tradiçōes concernentes ao modo como 
os fenômenos da linguagem e, em especial, os gramaticais, eram encarados já há três mil anos. Com efeito, até o advento do Cours de Saussure e da Linguística Estrutural, as pesquisas empreendidas acerca da linguagem, além de motivadas por fatores outros que não a língua por ela mesma, pouco mais faziam além de apresentarem descrições ou notações do sistema de regras inerente a uma língua natural, por meio do qual se ordenam os signos e se constituem os morfemas, palavras, enunciados e textos considerados aceitáveis por seus falantes nativos (cf. CHOMSKY, 2002). Em outras palavras: a Protolinguística ia muito pouco além do que atualmente compete ao âmbito das gramáticas científicas ou descritivas.

Ao lado de uma pluralidade de modelos teóricos de descrição gramatical de natureza vária que se deu a conhecer no século passado, a Gramática Tradicional, como parâmetro de estudo dos fenômenos de organização morfossintática da língua, continua presente, desde a Antiguidade, tanto na academia, onde alguns de seus aspectos (conceitos, jargão) sobrevivem, reaproveitados e mesclados a novas propostas em modelos mais recentes, quanto no sistema educacional brasileiro de base onde, em um número considerável de casos, constitui ainda a única perspectiva teórica abordada (e didatizada) no processo de ensino e aprendizagem de gramática. Apesar dessa familiaridade milenar com a Gramática Tradicional no Ocidente, ainda é amplamente difundida uma compreensão errônea desse modelo de notação gramatical, percebido, no mais das vezes, como um conjunto de regras necessariamente prescritivas de como produzir linguagem verbal (falada ou escrita), o que ignora sumariamente que

a língua não é um conhecimento estático. A competência linguística não é um produto acabado, nem tampouco um conjunto de regras (intuídas pelo falante de determinada língua natural) imutáveis no tempo e no espaço. Há fatores de natureza psicológica que interferem, de maneira direta, no conhecimento e no uso linguísticos. Fatores que não devem ser desconhecidos, nem tampouco negligenciados no processo de ensino/aprendizagem (JOVANOVIC, 1986, p. 146).

Esse entendimento do que viria a significar "gramática", além de unidimensional, é incompleto e insuficiente até mesmo para designar o conceito de "Gramática Tradicional”. Este último é, como se verá a seguir, com assiduidade 
baralhado, sob um prisma conceitual, num processo em que não se distingue seu caráter prescritivo advindo da "normalização", como fenômeno de origem e motivação externas ao sistema linguístico, de sua própria constituição como modelo teórico descritivo, não sem suas falhas e limitações de arrasto histórico.

Muitas vezes vilipendiada (o que se debaterá mais adiante), a GT tem servido como fonte de saberes (conceitos e terminologia), na contemporaneidade, para a elaboração de livros didáticos comunicativos e pós-comunicativos de alemão como língua estrangeira, com resultados satisfatórios, atestados pela continuidade de sua aplicação no último quarto de século, caracterizado pelo predomínio dos pressupostos teóricos e metódicos da Abordagem Comunicativa na elaboração de livros didáticos para o ensino/aprendizagem da língua suprarreferida (cf. JUNG, 2000). Nos itens que se seguem, verificaremos quais de seus pressupostos mantiveram seu lugar no âmbito do ensino de gramática em cursos comunicativos de alemão como língua estrangeira para adultos, mediante a adoção e o trabalho crítico com livros didáticos, ao lado de surgimentos próprios de outros modelos teóricos de descrição gramatical, e de que modo foram pedagogicamente adaptados para tais fins.

Antes disso, porém, uma revisão crítica da literatura acerca das vicissitudes da GT porá em relevo as questôes concernentes à temática da normatividade e descritividade de notaçôes gramaticais, bem como a questão de sua didatização.

\section{A normatividade como carater(ística) e não como definição}

O caráter prescritivo e normativo da gramática, concebida como forma de delimitação e imposição do que viria a ser o "correto" a ser aceito e memorizado (equivalente, por sua vez, à norma culta de uma variedade linguística regional e social) e sua discutível utilidade durante o ensino/aprendizagem funcional da língua, contribuiu - e ainda contribui - enormemente na formação de juízos de valor negativos acerca do estudo gramatical, tanto por parte de aprendizes que não se identificam com o objeto de estudo que lhes é paradoxalmente apresentado como sendo "sua língua", quanto por parte de professores e pesquisadores que, sobretudo durante as décadas em que prevaleceram os preceitos das abordagens direta e áudio-oral, praticamente eliminaram a menção à gramática em suas aulas de língua estrangeira (LE).

Como há pouco mencionado, o caráter prescritivo e normativo da Gramática que se conhece como Tradicional é uma atribuição de origem externa 
à língua que atende a objetivos igualmente extralinguísticos stricto sensu, de cunho político e educativo. É inequívoco, porém, que a notação gramatical motivada por tais fatores apresenta em si marcas claras dessa interferência, seja por meio da aplicação de seus conceitos e categorias de modo exclusivo a corpora de amostras linguísticas oriundas de linguagem escrita literária ideal selecionada (e faz-se imperioso sublinhar esse aspecto seletivo, pois, como denuncia Rocha (2002), afirmar que as regras gramaticais baseiam-se em obras literárias de escritores do Brasil e Portugal seria desconsiderar a abundância de desvios de norma também em seu seio, na forma de coloquialismos, regionalismos, etc.), seja através de declarações e instruções não mascaradas acerca do caráter supostamente não discutido das regras que explicita e exemplifica.

Neste ponto, considero oportuno questionar parcialmente a dicotomia descrição versus normatividade que se observa não rara vez na literatura dedicada a este tema. O escopo da gramática normativa não se opõe ao da outra mediante um princípio de descritividade. Pelo contrário, a gramática normativa descreve a variedade linguística ideal(izada) que concomitantemente prescreve, com base em uma tradição originada na Lógica aristotélica e em suas categorias do pensamento. Com efeito, Possenti (1996) ressalva que ambos os conceitos se confundem exatamente pelos traços distintivos da Gramática Tradicional. A mais pronunciada característica diferenciadora entre ambas as práticas reside justamente num ato alheio ao exercício da teorização gramatical, um ato de índole política, a saber, a atribuição arbitrária de um caráter normativo a determinada teoria gramatical a versar sobre um registro linguístico do qual foram extraídas as amostras constituintes dos corpora que subjazem à sua constituição. Esse ato político de normativizar, dissociado do descritivo, tampouco anularia a priori e per se o feitio potencialmente empírico ou científico de teorias erigidas à sua sombra, ainda que, na prática, o que se haja observado tenha sido a elaboração e difusão, ao longo de séculos, de uma Gramática Tradicional, de acordo com Saussure, logo ao início de seu Cours, como um "estudo desprovido de toda visão científica":

La science qui s'est constituée autour des faits de langue a passé par trois phases successives avant de reconnaitre quel est son véritable et unique objet.

On a commencé par faire ce qu'on appelait de la 'grammaire'. Cette étude, inaugurée par les Grecs, continuée principalement par les 
Français, est fondée sur la logique et dépourvue de toute vue scientifique et désintéressée sur la langue elle-meme; elle vise uniquement à donner des règles pourditinguer les formes correctes des formes incorrectes; c'est une discipline normative, fort éloignée de la pure observation et dont le point de vue est forcément étroit (1967, p. 13).

Molino (1984, p. 154) comenta, sobre a evolução qualitativa dos estudos linguísticos, que "le passage à une constitution scientifique ne pouvait se faire que par la séparation entre soucis normatifs et volonté de description objective" - vontade essa que haveria conduzido Franz Bopp à inauguração de um método de trabalho gramatical ou filológico comparativo "par le biais de l'histoire", ao investigar o desenvolvimento de fenômenos a partir de sua origem (op. cit., p. 155).

Bagno (2001) não hesita em afirmar que os componentes da gramática normativa (classificações, terminologia, conceitos, etc.) não constituem resultados de hipóteses científicas postas à prova e empiricamente comprovadas. Já Raster (2010, p. 4) faz diversas referências, ao longo de seu artigo Der Ursprung der Grammatik..., aos estudos linguísticos de índole gramatical, assim como conhecidos em várias épocas de predomínio de perspectivas normativas, como ciências: "Unter den sechs ursprünglichen Disziplinen des vedischen Wissenschaftssystems ist die Grammatik das grundlegende", na alusão à notação gramatical prescritiva empreendida pelos Três Sábios da Índia antiga. Em referência aos romanos, afirma que

[sie] konsolidierten die grammatische Wissenschaft, die bei den Griechen noch einen sehr fragmentarischen Charakter hatte, und schufen die stabilen Fundamente, auf denen die europäische Sprachwissenschaft aufgebaut werden konnte (2010, p. 6).

A discussão sobre a cientificidade da gramática normativa, longe de estar encerrada, não parece poder-se basear numa concepção específica e unívoca de método científico. Como observa Welsch (2007, p. 241),

um simples olhar sobre os métodos utilizados nas Geisteswissenschaften ensina que também não existe uma clara possibilidade de delimitação metodológica das Geisteswissenschaften. A pesquisa histórica exige outros procedimentos do que a verificação sistemática, métodos 
hermenêuticos opõem-se aos desconstrutivistas e mesmo no interior de um único modelo metodológico existem divergências consideráveis. Em contrapartida ao pluralismo metodológico, houve, certamente, diversas tentativas de estabelecer um método unificado para as Geisteswissenschaften (...), mas o resultado paradoxal de tais esforços de unificação é que eles mesmos ocorrem de maneira plural, recriando e potencializando ironicamente a situação à qual pretendem dar um fim.

O autor menciona ainda Thomas S. Kuhn que, em sua obra Die Struktur wissenschaftlicher Revolutionen,

demonstrou que a história das ciências naturais, assim como a história das Geisteswissenschaften e a das artes, é caracterizada por uma sucessão de períodos revolucionários, nas quais é alterada a base, e de períodos cumulativos, nos quais se prossegue o trabalho sobre a base alcançada. [Nas esferas das Humanities, Kuhn observou que] "a periodização por rupturas revolucionárias de estilo, gosto e estrutura institucional” pertence há muito tempo aos "instrumentos padrão". (op. cit., p. 239-240. Trechos entre aspas de Kuhn, 1967, como citado por Welsch).

Dacanal (1987, p. 28), partindo de outro viés, questiona a distinção entre gramática normativa e descritiva, a qual reduz a um

sofisma resultante de um pressuposto idealista implícito: o de que um indivíduo tem a liberdade de falar e escrever como quiser. Isso é uma falsidade evidente e quem afirma tal coisa só pode ser um ingênuo ou um insano. E expor as normas que regem uma língua ou impô-las são, portanto, atos por natureza idênticos. A única diferença que pode existir é que no primeiro caso a forma de imposição é mais sutil. (...) Uma língua é, também, e essencialmente, um fenômeno social e político.

É neste ínterim que se inserem os comentários de autores que sublinham os problemas da Gramática Tradicional (ou GT) como abordada na escola brasileira - e não só nela. Segundo Suassuna (2002), essa abordagem se baseia numa visão preconceituosa e purista da língua como unissistema estático e 
desprovido de diversidade de registros e usos, em censuras e definições precárias, sem espaço a discussões de regras. Para Perini (2000), muitos dos preceitos da Gramática Tradicional também careceriam de lógica, enquanto Ruwet (1975) denuncia uma preocupação insipiente da GT em descrever as regularidades que caracterizam a ordenação do sistema linguístico; em vez disso, ela dedicar-se-ia a exibir enfaticamente paradigmas de formas irregulares ou excepcionais. A crítica à prescritividade e normatividade da Gramática Tradicional é, sem lugar a dúvida, a mais comum.

Quanto à norma, convém considerar a distinção que estabelece Leite (2006, p. 19) - após citar Hjelmslev para desaconselhar a confusão desta com o uso - entre normas explícitas, relativas "apenas a um dos possíveis usos da língua”, eleito como bom e superior aos demais, e aquelas implícitas, referentes "a todos os outros usos". Suas reflexões se inserem no âmbito de um trabalho acerca do purismo linguístico, definido pela autora como "um fenômeno que surgiu com o estabelecimento, em uma dada língua, de um modo de falar ou de escrever 'melhor' do que os demais" (idem). Assim pormenorizado, esse fenômeno, da ordem da normatização, distingue-se eideticamente do ato de descrever. Ele gera, porém, a tradicionalização - e o conservadorismo da tradição estabelecida.

Quanto ao conceito de tradição, retomo Bornheim (1987), segundo quem o verbo latino que origina o termo, tradire, significaria inicialmente "entregar" - tendo ainda dado origem, devo acrescentar, ao verbo português "trazer". Daí deriva a noção de passar algo - o dito - a alguém, ou um conhecimento a uma nova geração. Em sua base, esse movimento se plasma na mudança, sob forma de uma reconstrução conduzida pelos indivíduos transmissores das tradições culturais. A GT, como conjunto de saberes metalinguísticos, ou melhor, como uma perspectiva de recorte e análise de fenômenos linguísticos de cunho gramatical, representa a mais antiga, duradoura e enraizada tradição de metalinguagem propriamente dita de que se tem notícia no Ocidente. Percebese que, na contemporaneidade, malgrado a presença de uma variedade de modelos alternativos de análise e descrição gramatical, tais como a Gramática de Constituintes Imediatos, a Gerativo-transformacional, a de Dependências/ Valências, etc., a GT vinga, ao lado destas últimas, na escola, na universidade, nos livros didáticos de língua materna e estrangeira, na mente de alunos e professores. Entrementes, hoje se podem observar algumas mudanças paradigmáticas no que 
tange ao modo como os usuários desse modelo de descrição lidam e podem lidar com ele. Em livros didáticos (LD) de alemão LE, à guisa de exemplo, é uma constante, desde o movimento comunicativo de finais dos anos 70 que veio a perfilar praticamente toda a produção de novos LD dessa língua a partir dos anos 80 , o recurso tanto a elementos da GT quanto à Gramática de Valências quando da necessidade de explicitação/conscientização referente a itens gramaticais, elementos esses que são selecionados e postos em diálogo pelos autores seguindo critérios pedagógicos. Claro está que a natureza dos conhecimentos metalinguísticos necessitados por aprendizes de uma LE que visam ao seu uso na prática da comunicação quotidiana e comercial, ao contrário daquela dos cultivados por linguistas, professores de língua e estudantes de Letras, não precisa apresentar sinais de uma coerência interna com os pressupostos próprios de um único modelo. Elementos advindos de diferentes teorias gramaticais acabam sendo mesclados, desde que essa prática combine uma série de requisitos facilitadores da aprendizagem, por parte do alunado, de uma "gramática funcional", de certas regras e padrões de funcionamento morfossintático da língua que auxiliem os aprendizes na construção de enunciados e que possam ser estendidos a vários usos e contextos. Esse fato indica uma mudança de postura em face da GT: seus pressupostos passam a ser aplicados com maior flexibilidade, e não necessariamente ensinados como regras imutáveis e sagradas. Ora a distinção sujeito/predicado, advinda da GT, pode vir a ser de maior valia na transmissão de determinados conceitos aos alunos, ora parece ser a referência a actantes e circunstantes, sem menção a "sujeitos", "predicados" e "complementos", própria da Gramática de Valências, muito mais auxiliar ao processo de explicitação de certos fenômenos gramaticais e conscientização dos aprendizes acerca de seu escopo. Apesar destas considerações, é importante registrar que a referência à terminologia e a conceituações advindas de modelos teóricos de descrição gramatical dista de constituir parte essencial ou obrigatória do ensino de gramática, e sabe-se que o excesso de tais referências pode chegar a dificultar o processo de ensino/aprendizagem. A despeito disso, estas reflexões se inserem num contexto, o de ensino de LE a partir do advento da Abordagem Comunicativa e, como exemplo destacado, o âmbito dos LD de alemão LE, em que o recurso a terminologias e conceituações de índole gramatical é ampla e invariavelmente incluído em ditos LD. E é com o reconhecimento dessa realidade que analiso a presença constante de elementos próprios da GT em LD elaborados em "tempos modernos", nos quais conhecimentos 
sociolinguísticos e uma multiplicidade pacífica, complementar e dialógica de teorias, modelos e visões acerca dos fenômenos de índole gramatical nos livram das amarras da prescritividade outrora indiscutida e indiscutível.

Com base nessas reflexões, e antes de prosseguir abordando a questão "Por que será que ainda segue em aplicação a Gramática Tradicional no âmbito de um ensino de línguas 'moderno'?", reforço que não considero "Gramática Tradicional" e "gramática normativa" parassinônimos a priori ou, ao menos, de forma necessária. Na prática, é evidente que os dois termos se sobrepõem em termos de uso e parecem chamar a atenção para um mesmo referente. Entretanto, em termos de especificidade conceitual, julgo necessário estabelecer uma distinção entre Gramática Tradicional como um modelo teórico que sistematiza as regras de uma língua pelos seus princípios e categorizações, e normatividade como o ato de imputar a algo - inclusive a um modelo gramatical - um caráter prescritivo, da ordem de uma lei da adequação no uso da língua.

Essa dissociação permitiria a tomada em consideração, sem culpa, de aspectos e elementos da Gramática Tradicional durante o ensino tanto de língua materna quanto de língua estrangeira, embora nos interesse mais concretamente o segundo caso, de forma liberal, a contemplar, sobretudo, dois enfoques básicos:

a) a eventual adoção, adaptação ou aproveitamento de nomenclaturas e diferenciações próprias da Gramática Tradicional, que pareçam convenientes como insumos teóricos a serem empregados para a elucidação de fenômenos linguísticos com base em critérios definidos de filtragem didática, tendo em conta características sociointerativas específicas dos contextos em que se dê o processo de ensino/aprendizagem, a saber: perfis discente e docente, tradiçôes culturais e usos e costumes pedagógicos do tópos em que se conduza dito processo, relação entre as língua de origem e destino, exigências e expectativas institucionais, etc.

b) a referência a aspectos dessa mesma Gramática, embora não exclusivamente dela, com enfoque normativo, quando da análise e estímulo à aprendizagem de registros linguísticos utilizados em situações que o exijam, dado, por exemplo, o seu grau de formalidade socioculturalmente institucionalizado.

De fato, a Gramática Tradicional (GT) será contemplada, aqui, como um entre muitos conjuntos de instrumentais teóricos disponíveis para sua aplicação no entorno do ensino de LE, de modo a contribuir, ao lado dos demais, na 
conformação do dinamismo e da flexibilidade que caracterizam os estudos da linguagem e a pedagogia de línguas em vigência. A referência a "conjunto" advém do reconhecimento do fato de que aquilo a que geralmente se faz alusão como GT é, na verdade, um grupo de notações gramaticais que guardam semelhanças fundamentais entre si sem, contudo, igualar-se por completo. Entre as similitudes, evidentemente, está sua origem comum: a tradição filosófico-metalinguística grega, as categorias aristotélicas, a gramática especulativa do medievo, as descrições renascentistas. Como se verá em maiores detalhes no próximo item, no âmbito da pedagogia de línguas estrangeiras a partir do século passado, o ensino de GT constituiu a base da Abordagem Gramática-e-Tradução. Com a derrocada desse método e sua substituição e rejeição a partir do surgimento das Abordagens Direta, Audiovisual e Audiolingual, bem como da kommunikative Wende, a descrição gramatical passou a ser abordada por outros enfoques e mesmo a ser menosprezada. Em meio ao atual dinamismo característico da Fase Póscomunicativa ou do pós-método (conceituação cf. KUMARAVADIVELU, 2006 e 2006a; SILVA, 2008, BORGES, 2010, entre outros), a GT soma-se a outras tradições e tem aspectos manipulados e aproveitados em sala de aula.

\section{Aspectos da teoria aplicados em livros didáticos contemporâneos de alemão LE}

"We frequently encounter the characterization that syntax is the study of the relations of words between sentences. This suffers from being a definition in terms of such undefined entities as words and sentences." (TWADDELL, 1983, p. 36).

A Gramática Tradicional, cujas categorizaçôes, como um todo, se baseiam em critérios de ordem semântica e não funcional, fundamenta-se na análise morfológica e sintática da língua e situa-se nos níveis da palavra e da frase, considerando a letra e a sílaba as unidades linguísticas anteriores à palavra. Como veremos logo adiante, tanto a conceituação de "palavra" quanto de "frase" são complexas e, entre os diferentes gramáticos e linguistas, distam da univocidade. O objetivos da GT, segundo Smyth (1956, p. 255 apud PERCIVAL, 1976, p. 229), seria demonstrar "how the different parts of speech and their different inflectional forms are employed to form sentences". Neste item serão abordados, 
entre outros aspectos da GT, os significados, nela, dos termos "palavra", "frase" e "partes da oração" (ou do discurso), mencionados por Smith neste excerto.

Com efeito, no contexto descritivo de uma mesma língua, a terminologia da GT tampouco se apresenta permanentemente constante de autor para autor, em matizações que vão desde a relativa parassinonímia (algo da ordem da adoção de "complementar" por parte de um gramático e da predileção por "acessório" por parte de outro, com referência ao mesmo fenômeno) a disparidades classificatórias ("aposto" como "complemento do nome" em FIGUEIREDO; GOMES FERREIRA, 1979, e como "termo acessório" em CUNHA; CINTRA, 1985 , etc.) indicadoras de pontos de vista dissemelhantes acerca de determinado aspecto da linguagem. Entre diferentes línguas e países, termos e conceitos variam de acordo com necessidades concretas próprias do sistema linguístico a ser descrito. Essas diferenças, contudo, não chegam a constituir submodelos teóricos nem protótipos independentes, de modo que, no geral, as obras coincidam na adoção dos preceitos básicos da GT advindos das tradiçōes greco-romana antiga, medieval e renascentista. Fugiria desmesuradamente do escopo deste trabalho dedicar este capítulo à investigação das formas do paralelismo (ou falta de) entre as diferentes GTs, tanto de uma mesma língua quanto em perspectiva intercultural de comparação, bem assim a dedicação de um esforço sistemático à busca das correspondências entre as terminologias atuais e suas origens em Dionísio, Varrão ou Quintiliano, por exemplo. Por isso, serão citados alguns casos dessas eventuais desconformidades sem caráter exaustivo, apenas à guisa de ilustração.

A vastidão conteudística terminólogico-conceitual da GT, malgrado suas tão frequentemente apontadas faltas, é tal que impossibilita a abordagem citerior de sua totalidade. Assim, com vistas a delimitar o alcance das explanações dentro da mira deste trabalho, adoto o critério de restrição expositiva, quando necessário, aos elementos relevantes ao contexto do ensino de alemão LE, com base na metalinguagem diretamente abordada nos mais comumente adotados livros didáticos comunicativos.

\subsection{Frase, oração, período e Satz}

Em comum, diferentes definições de frase costumam salientar, mediante distintas formulações, sua condição de enunciados linguísticos que expressam sentidos ou expressões comunicativas completos, independentemente de sua constituição interna ou extensão (CUNHA; CINTRA, 1985; CÂMARA 
JÚNIOR, 1986; BECHARA, 2010; CEGALLA, 1998; ABAURRE et al., 2003). Outra característica das frases, mencionada por diversos estudiosos, é o fato de terem início e fim. Esse traço, bem como a imprecisão generalizada das noções de frase, foi ironizado na definição de Perini (1995, p. 61-62), segundo quem "a frase é delimitada por uma maiúscula no início e por certos sinais de pontuação (./?/!/...) no final”. Uma frase pode, assim, ser composta por palavras de qualquer classe, em qualquer número: “Oi!", “Ai!”, etc. seriam, portanto, exemplos de frases portuguesas. Tradicionalmente entende-se que as frases desprovidas de um predicado, de natureza averbal, tais como os exemplos recémcitados, são de categorial nominal. Por sua vez, as frases que contêm um predicado e, com frequência, um sujeito, são classificadas como verbais e alçadas à categoria de orações. Em alemão, o vocábulo Satz pode corresponder, em determinados contextos de tradução, tanto a "frase" quanto a "oração" em português. Entretanto, a Duden: die Grammatik, obra de referência na Alemanha (cf. FLIEGNER, 1986), estipula a correspondência de Satz a "einen bestimmten grammatischen Bau; dieser ist haupsächlich vom Verb bestimmt: Das Verb eröffnet um sich herum Stellen für weitere Bestandteile des Satzes" (1998, p. 609), o que aproxima Satz muito mais a "oração", de acordo com as noçōes aqui expostas. Apesar disso, a definição de Satz no seio dos estudos sintáxicos conduzidos na Alemanha é não menos complexa que a de "frase" na tradição lusófona, sendo ainda especialmente complicada, diga-se de passagem, pelo fato do caráter proteiforme de Satz incluir potencialmente o significado atribuído a "oração". Como afirma Dürscheid (2007, p. 57),

Wird der Satz [...] rein syntaktisch als eine verbindung aus mehreren Wörten definiert, so ist zu fragen, ob Einwortsätze Sätze (vgl. Feuer!) darstellen. Diese Frage stellt sich auch dann, wenn man Sätze als eine grammatische Einheit aus Subjekt und Prädikat definiert. In einer orthographiebezogenen Definition wird der Satz als eine durch Interpunktion und Anfangzgroßschreibung markierte Einheit gesehen. [...] Interessant ist, dass im Englischen und Französischen - anders als im deutschen - terminologisch ein Unterschied gemacht wird zwischen dem Satz als orthographische und dem Satz als grammatische Einheit. Die orthographische Einheit wird als ,sentence' (engl.) bzw. ,phrase' bezeichnet, die grammatische Einheit als ,clause‘ (eng.) bzw. ,proposition` (frz.). 
A autora propõe, mais adiante, uma definição de Sätze em que estas figuram como unidades linguísticas relativamente independentes e, em geral, integradas em unidades maiores (textos), compostas de Phrasen, correspondentes ao português "sintagma" (esse termo de origem grega, correspondente ao eixo sintagmático da linguagem em Saussure e fundamental na teoria chomskyana, não participa da nomenclatura da GT escolar brasileira ou alemã, a menos que por iniciativa integradora de ordem da filtragem pedagógica conduzida por docentes e atores de material didático). Dürscheid nos lembra, assim, da distinção empreendida na GT entre einfache Sätze e komplexe Sätze. Normalmente, pode-se estabelecer um paralelo entre as primeiras e as frases nominais do português, ao passo que as segundas coincidiriam grosso modo com nossa definição tradicional de oração. As frases, constituam ou não orações, podem-se classificar de acordo com uma série de critérios, temática que não abordarei exaustivamente aqui, dadas as limitações próprias do escopo deste trabalho. Em sua classificação mais basilar, definida por critérios de entoação, morfossintáxicos e ortográficos, podem ser consideradas de natureza declarativa (Aussagesätze ou Deklarativsätze), imperativa (Aufforderungssätze ou Imperativsätze) ou exclamativa (Ausrufesätze ou Exklamativsätze), em correspondência, como relembra Luft (1987), às faculdades da inteligência, vontade e sensibilidade, associadas, respectivamente, às funções intelectiva, volitiva e emotiva da linguagem. Além destas, diferenciamse ainda as categorias intermediárias das oraçōes interrogativas (Fragesätze ou Interrogativsätze) e optativas (Wunschsätze ou Optativsätze).

Uma oração corresponde, na GT, a um período simples - nele, constitui uma oração absoluta. Concatenadas, as orações podem formar períodos compostos, por coordenação (Hauptsätze), subordinação (Nebensätze) ou uma combinação de ambas as formas. Associa-se à coordenação a sequência de orações sintaticamente independentes unidas ou não por meio de conectivo conjuncional (no primeiro caso, subclassificadas como sindéticas e, no segundo, como assindéticas). No alemão, a identificação das Haupt-e Nebensätze é facilitada por traços sintáxicos claramente decifrados mediante a verificação da posição do verbo na frase (ou do auxiliar, no caso de estruturas compostas por mais de um) encontrando-se este último, no caso das segundas, sempre no final da oração. A taxonomia das oraçóes principais e subordinadas é complexa, e apenas a uma pequena parte dela costuma-se aludir em livros didáticos de alemão LE. Da tipologia das Hauptsätze pouco ou nada se ouve; da classificação das Nebensätze de acordo com critérios funcionais em Subjektsätze, Objektsätze, Adverbialsätze, 
Attributsätze e Prädikativsätze, são frequentes, porém, as referências a alguns dos subtipos das orações adverbais, tais como Finalsätze, Konzessivsätze, Modalsätze e Konzessivsätze. Eventualmente, como se observa em studio d A2 (Funk et. al, 2008), critérios de filtragem pedagógica e didatização das classificações oracionais geram denominações alternativas e extraoficiais sob o ponto de vista da GT, como "dass-Sätze", "um...zu-Sätze" versus "damit-Sätze" (algo como "oraçōes iniciadas com 'que", "orações iniciadas com 'a fim de", etc.).

\subsubsection{Termos essenciais da oração}

Os elementos, termos ou partes da oração (Satzglieder) considerados essenciais ou fundamentais na Gramática Tradicional são o sujeito e o predicado, sustentando-se no segundo a oração. Em regra define-se o sujeito como aquilo (ou aquele) a respeito de quem se declara algo, e o predicado, como a declaração acerca do sujeito (Satzaussage). Embora existam controvérsias quanto à exatidão desse conceito, os aprendizes de alemão se valem de um critério distintivo específico das línguas nominativo-acusativas com flexão de caso com vistas ao reconhecimento do sujeito, a saber, a sua identificação com o nominativo. Esse critério é controverso, porém, na medida em que os predicativos alemães também se apresentam nesse caso, o que dificulta a discriminação entre sujeito e predicativo em oraçôes como "Peter ist der Lehrer" ou "Der Lehrer ist Peter". Tanto em português quanto em alemão, o sujeito, quando presente, concorda em número e pessoa com o verbo, sendo comuns em ambas as línguas as orações desprovidas de sujeito, nas quais se conjuga o verbo na terceira pessoa do singular ("Relampeja", em português, e "heute wird gesungen", em alemão). Nesta última língua, verbos que indicam fenômenos climáticos (entre alguns outros denominados impessoais) pressupõem como sujeito o pronome pessoal "es", desprovido de significado específico na oração (e de um referente), didatizado em studio d $A 1$ (FUNK et. al, 2005) como "Wetterwort 'es" (algo como "palavra do tempo 'es"). Pela existência não problemática de orações sem sujeito nessas línguas, pode-se deduzir que, de fato, o elemento considerado "mais fundamental" da frase verbal ou komplex seja, por excelência, o predicado. Nele, a posição central é ocupada por, no mínimo (caso dos predicados simples ou einteilig), uma forma verbal finita, que se pode associar a outras palavras e formar um predicado composto (mehrteilig). Zweiteilige Prädikate são especialmente comuns e de fácil visualização na língua alemã, devido ao posicionamento regular do verbo principal 
(Hauptverb) e do auxiliar (Hilfsverb), respectivamente, ao fim da frase e na segunda posição em tempos verbais compostos como Aktiv Perfekt Indikativ e Konkunktiv, os tempos verbais na voz passiva, Indikativ Futur I Aktiv, etc.

\subsection{Tipos de predicado}

Catalogam-se os predicados como verbais, nominais ou verbo-nominais, de acordo com qualidades da significação de seu verbo nuclear. Se considerado um verbo de significação definida, determinará a classificação do predicado como verbal; se necessitar a complexão de seu significado por outra palavra, fará que se denomine o predicado "verbal" e, em caso de exigir tanto um complemento para o verbo quanto um predicativo do sujeito, receberá o terceiro qualificativo supramencionado. A compleçáo do sentido do verbo em predicados nominais (em referência ao sujeito) e verbo-nominais (em referência ao objeto) se dá por ação dos predicativos (Prädikativ ou Prädikativum) do sujeito (Subjektprädikativ em HELBIG; BUSCHA, 1996 e Prädikatsnomen em BUßMANN, 1990). Já nos predicados verbais que contenham verbos transitivos e nos verbo-nominais, em seu turno, por meio dos objetos.

\subsubsection{Transitividade e termos integrantes da oração}

Os verbos transitivos são aqueles em que a ação expressa implica um caminhar, um trânsito até um objeto, de forma direta ("Fulana gosta o café", no sentido de "prova, experimenta", de modo imediato) ou indireta ("Sicrano gosta de café", no sentido de apreciar, i. e., haver transitado indiretamente à apreciação a partir da ação inicial de experimentar). Em geral ensina-se, no caso do português, a distinguir os objetos indiretos dos diretos pela preposição que preponderantemente os antecede. Verbos do dizer, dar, enviar, etc. são classificados como transitivos diretos e indiretos (ditransitiv). $\mathrm{O}$ fenômeno da regência verbal e transitividade em alemão (Transitivität) pode ser - é - associado morfologicamente aos casos. Assim sendo, um direktes Objekt condiz com um Akkusativ-Objekt e, por sua vez, um indirektes Objekt corresponde a um DativObjekt e aos mais raros Genitiv-Objekte, de modo geral vertidos em dativos na língua falada e habitualmente mesmo na escrita. Vale lembrar que, assim como se observa em português no caso dos objetos diretos, apenas os acusativos do alemão tornam-se sujeitos em reformulações da oração na voz passiva. Quanto 
aos verbos que exigem complemento preposicionado, todos entram na categoria dos Präpositional-Objekte. Em ambas as línguas, são intransitivos os verbos que não exigem objeto direto ou indireto, acusativo ou dativo, como os verbos do mover-se, dormir, nascer e morrer, indicadores de fenômenos climáticos, entre muitos outros. A referência à transitividade verbal não é comum em livros didáticos de alemão LE. Eventualmente encontra-se menção direta a ela em Übungsgrammatiken ("gramáticas de exercícios") que abordam a diferenciação entre as formas verbais regulares em face de irregulares de verbos ora transitivos, ora intransitivos ("Er hat alle erschreckt" contra "Er ist wegen des Sturms erschrocken", a título de exemplo). Em grande parte dos LDs de alemão LE, desde os anos 80, é comum o recurso a elementos próprios da Gramática de Dependências/ Valências, como a referência a actantes (Ergänzungen) com referência tanto a sujeitos como a objetos das orações (exemplos: AUFDERSTRAßE, 2000 e 2000a; NEUNER et al., 1988; FUNK et al., 2005 e 2008, etc.).

Consideram-se também termos integrantes da oração o agente da passiva (auktorale Adverbiale Bestimmung, em alemão) e o complemento nominal. A problemática típica do ensino de português como língua materna que se instaura diante da confusão adjunto adnominal/complemento nominal mostrase irrelevante no contexto de ensino de interesse deste texto, bem como a explanação do segundo.

\subsubsection{Termos acessórios da oração}

Constituem os termos acessórios da oração o adjunto adnominal, o adjunto adverbial (determinativo e atributivos) e o aposto. A referência a adjuntos adverbiais, no caso do ensino de alemão LE, dá-se em geral indiretamente, através da adoção do portmanteau "TeKaMoLo", pequena "fórmula" didática comumente ensinada aos alunos para que memorizem a ordem normal dos tipos de advérbios na frase (temporal, causal, modal, local). Nesse caso, ignoram-se, em razão de não se recortarem e nomearem de forma específica, outros tipos mais especializados e talvez menos frequentes (instrumental, final, condicional, consecutivo, adversativo, autoral, etc., correspondendo, este último, ao agente da passiva do português). Por sua vez, tampouco é usual a alusão direta a atributos e determinantes em livros didáticos de alemão LE. Faz, porém, referência às funções atributiva e predicativa dos adjetivos, para distinguir os casos em que palavras dessa classe são declináveis ou não. 
A menção aos adjetivos nos leva a uma parte essencial da GT, a saber, a categorização das classes de palavras.

\subsection{As palavras}

Não menos complexa que a definição de frase o é a de palavra, termo intuitivamente usado na linguagem quotidiana para indicar algo (tão vago e impreciso, note-se) como "a basic element of language" (BUßMANN, 1996, p. 1285). São muitos os critérios e possibilidades de definição de "palavra" abordados pelos linguistas, e essa multiplicidade é de difícil redução a um conceito de ampla adoção (cf. SAUSSURE, 1967; SCHUNK, 1997; CÂMARA JÚNIOR., 1967; LYONS, 1968; BASÍLIO, 1999, 2004; TWADDELL, 1983; BUßMANN, 1996, etc.). Apesar destas dificuldades, a importância do estudo da palavra é especialmente sublinhada e posta em categoria superior às do som e da frase por Eisi (1995), para quem falar consiste basicamente em utilizar palavras. É evidente, contudo, que a inter-relação entre as distintas instâncias da realização linguística não dá lugar à eleição de apenas um tipo de elemento com base em uma sorte de critério como o "mais importante" para a comunicação. A Gramática Tradicional, porém, desconhecedora do morfema e do sintagma, elege as palavras como unidades básicas da língua, e inicia por elas sua descrição.

Em seu dicionário, e relevando os postulados das diferentes subáreas da Linguística contemporânea, Bußmann (1996) menciona as principais sugestóes de definição de "palavra" de acordo com o seu nível de descrição:

(a) phonetic-phonological level: words are the smalles segments of sound that can be theoretically isolated by word accent and boundary markers like pauses [...] and which are further isolated on a

(b) orthographic-graphemic level by blank spaces in writing or print;

(c) on the morhological level, words are characterized as the basic elements of grammatical paradigms like infection [...], they are structurally stable and cannot be divided;

(d) on the lexical-semantic level, words are the smallest, relativelly independent carriers of meaning that are codified in the lexicon, and (e) can be described syntactically as the smalles permutable and substitutable units of a sentence (op. cit., id.). 
Para cada um desses recortes há vozes que se alçam apontando poréns, matizes e exceções. Em seu turno, o contraste interlinguístico porá em evidência a insuficiência de cada critério por si só (à luz do critério b, "sugar free" são duas palavras em inglês e "zuckerfrei", uma em alemão; eventuais ocorrências da grafia da primeira como "sugar-free" transformam agora a locução em "uma palavra"? Já de acordo com o critério c, todas essas formas constituiriam palavras únicas, uma vez que tampouco se pode dividir a forma "sugar free" por meio da inserção de qualquer elemento entre suas duas partes componentes). No livro didático de alemão como língua estrangeira Berliner Platz A1 (LEMCKE, C. et al., 2005), uma visão mais tradicional e alinhada com o critério (b) de Bußmann é apresentada ao aluno, por meio de um diálogo em que se comenta que aquilo a que se refere em alemão como "Telefonkarte", mediante uma única palavra, necessita três, na língua francesa, para ser expresso ("carte de téléphone") ignorando-se, aqui, o uso amplamente difundido na França da forma "télécarte" e quaisquer outras noções possíveis de "uma palavras".

A definição de palavra na Gramática Tradicional coincide mais, grosso modo, com as formas livres mínimas de Bloomfield (1926), em oposição às formas presas (e, acrescento, aos morfemas), embora sua definição não dê conta da análise dos Komposita alemães, ou mesmo dos substantivos compostos portugueses, divisíveis em formas livres justapostas. Na Gramática Tradicional, que ignora os morfemas e cujas origens precedem o alçamento dos últimos a foco central de interesse da Morfologia, as palavras são as unidades mínimas passíveis de análise, cujos paradigmas são estudados com base em categorizações de cunho nocional, as "partes da oração". Protágoras e Platão coincidiam em reconhecer duas grandes partes da oração; Quintiliano distinguiu onze e Dionísio, por sua vez, oito. Embora inexista um consenso quanto a quais venham a ser as partes da oração na GT e mesmo com respeito à sua validez classificatória (cf. GONZÁLEZ CALVO, 1982), observa-se que, em geral, consideram-se, nos âmbitos lusófono e germanófono, que estas compreendam as classes do artigo (Artikel), substantivo (Substantiv), pronome (Pronomen), adjetivo (Adjektiv), verbo (Verb), advérbio (Adverb), preposição (Präposition), conjunção (Konjunktion) e interjeição (Interjektion). Em si, a nomenclatura das classes de palavras na GT varia muito pouco entre um e outro autor e entre o português e o alemão, o que se deve ao fato de serem oriundas, nesse estado atual, das categorias aristotélicas dos modos de ser, donde advém o paralelismo substância/substantivo, qualidade/ adjetivo, ação/verbo, paixão/voz passiva, cópula/verbos copulativos, circunstâncias/ 
advérbios, etc. (cf. JOLIVET, 1984). A temática das Wortarten se introduz, na Duden-Grammatik (1995, p. 88), como segue:

Auf Grund der unterschiedlichen Funktionen im Satz und der damit eng verknüpften Formmerkmale, Anordnung und Beziehungen zueinander können verschiedene Gruppen oder Klassen von Wörtern unterschieden werden, die sich auch semantisch voneinander abgrenzen lassen und die man Wortarten nennt.

Advérbios, conjunções e proposições são agrupados, na obra suprarreferida, como tipos de partículas (Partikeln) (cf. idem, passim), e pertencem às classes de palavras invariáveis. Verbos (Vollverben, Hilfsverben - auxiliares e Modalverbenmodais) são conjugáveis de acordo com uma série de parâmetros (tempo, aspecto, modo, voz, pessoa, número). Por sua vez, as demais classes variáveis, tanto em português quanto em alemão, são flexionadas em gênero, número e grau (artigos tão somente em gênero e número). Ao alemão, some-se a flexão de caso.

O estudo da classe de palavras no âmbito do alemão LE se inicia, habitualmente, por substantivos e adjetivos, com ênfase nos três gêneros (masculino, feminino e neutro) e aos "dois números" (singular e plural). No caso dos substantivos, é já tradicional apresentar, logo nas primeiras unidades, aspectos basilares da formação de compostos e, no espectro dos artigos, os definidos, indefinidos, negativos e possessivos (em geral conhecidos pelos aprendizes brasileiros como pronomes - de fato, na GT alemã, encontram-se menções tanto a Possessivartikel quanto a Possessivpronomen, refletidas em diferentes livros didáticos de LE). Quanto aos verbos, principia-se obviamente pela conjugação de "sein" no presente e, embora a introdução dos demais verbos tenda a obedecer, como a de todos os conteúdos gramaticais na abordagem comunicativa, a critérios funcionais de necessidade, observa-se uma inclinação a evitar aqueles cuja regência implique a apresentação antecipada de exemplos que contenham flexões em casos outros que não os já explicitamente abordados em curso.

\section{Considerações finais}

As reflexóes contidas neste texto, em vez de uma defesa da GT como modelo de descrição gramatical, tanto como fundamento teórico de análise de fenômenos linguísticos quanto como modelo aplicável a LDs de LE, constituem 
uma tentativa de desmistificação de certos conceitos e até juízos de valores que lhe são comumente atribuídos. Uma revisão da literatura acerca da GT demonstra que é muito frequente a associação imediata Gramática Tradicional/ gramática normativa, por parte de diversos autores, como se esse binômio consistisse numa ocorrência de parassinonímia. Em vez disso, defendo a ideia de que normatividade e prescritividade são atribuiçôes de cunho extralinguístico, de ordem política e ideológica que, ao longo dos séculos, estiveram atreladas à GT e à transmissão de seus pressupostos em sala de aula. Apesar disso, como modelo de notação gramatical, a GT, salvaguardadas suas limitações ou imprecisões, não passa de mais uma teoria metalinguística que, na atualidade, convive lado a lado com outras que se mantêm igualmente à disposição de pesquisadores, autores de LDs e docentes para sua utilização no exercício reflexivo acerca de fenômenos da ordenação da linguagem ou de sua pedagogização. Muitos dos conceitos advindos da GT correspondem a categorias lógicas do pensamento, assim como formuladas desde a Antiguidade Clássica e, eventualmente, mantêm sua validez e aplicabilidade para a didatização de alguns conteúdos de natureza gramatical, com bons resultados. Um reflexo disso é sua continuada adoção, no âmbito dos LDs dedicados ao ensino de alemão LE, ao lado de outros modelos gramaticais, com destaque para a Gramática de Valências, observável na ampla presença de referências diretas a elementos terminológicos próprios da GT, como a alusão às classes de palavras, tipos de orações e alguns de seus constituintes. Os próprios modelos gramaticais mencionados neste texto contêm, em seu seio, traços advindos da GT, cujas origens se confundem com a própria gênese dos estudos (meta)linguísticos na história da humanidade.

O grande erro nocional e pedagógico reside, como nos lembra Bechara (1998), no adotar-se a visão da variante linguística descrita pela gramática normativa como opção exclusiva (e, adiciono, impraticável) de uso da língua, como a própria língua em sua totalidade histórica. É assim que Neves (2002, p. 231), Possenti (1996), Câmara Júnior (1986) e Tavaglia (2001) defendem o ensino da gramática normativa como forma de ofertar ao aluno também o conhecimento da variedade culta (e escrita) da língua e a dele advinda capacidade de adequação a contextos e situações que lhe permitam "ocupar posições na sociedade", pelo prestígio, papel social e indiscutível condição de veículo de parte considerável da produção cultural associados à norma culta da língua. Além disso, deve-se considerar o fato de que a GT, como modelo teórico, é aplicável a quaisquer variantes linguísticas que se pretendam analisar/ensinar. Um 
enunciado como "Os cara foro lá e mandaro vê" segue tendo, no caso de haver interesse em aplicar a GT para sua análise, um sujeito, um predicado, dois verbos, um substantivo, uma conjunção; constitui um período composto, etc.

Creio fazer-se imperioso considerar, na atualidade, o papel fundamental desempenhado pelo professor crítico (ou intelectual, cf. SILVA, 2008), munido de bons conhecimentos (meta)linguísticos e pedagógico-metodológicos no processo de manipulação da grande variedade de instrumentais teóricos disponíveis para sua veiculação em contextos de ensino/aprendizagem. Como afirma Cagliari (1996: 30), "quem lida com o ensino de linguagem tem que saber Linguística" - e, acrescente-se, Didática/Metodologia de Ensino. É assim que, preconceitos e atributos extralinguísticos à parte, o melhor de cada modelo teórico e da experiência prática compartilhada entre profissionais, como um todo, conduzirá o ensino de gramática a caminhos flexíveis delineados para que se atinja de modo ótimo o objetivo maior do ensino comunicativo de línguas: o aprendizado de conteúdos gramaticais funcional e integrado ao desenvolvimento das habilidades e capacidades comunicativas que ofereça ao alunado instrumentos para a expressão adequada e autônoma nos contextos em que se servirá da língua na "vida real". E, como se vem observando no âmbito do ensino de alemão como língua estrangeira para adultos mediante a adoção de livros didáticos, a GT tem sido de valia, mediante uma adoção e adequação criticamente selecionadas e flexíveis de vários de seus conceitos e termos, em processos de conscientização dos aprendizes acerca de determinadas regras de funcionamento da língua. Entre outros fatores implicados nesse fenômeno encontra-se o fato de que a GT permanece sendo a fonte da maior parte dos préconhecimentos metalinguísticos que os estudantes trazem consigo para a sala de aula de LE. Como preconizam as reflexóes centrais pertencentes do arcabouço teórico de base da Abordagem Comunicativa (Análise do Discurso, Construtivismo de Piaget, Sociointeracionismo de Vygotsky, Psicologia Humanista de Rodgers, etc.), não convém esquecer que o processo de ensino/aprendizagem é dialógico e os saberes, crenças, emoções e noções de mundo dos alunos constituem parte fundamental dessa troca. 


\section{Referências}

ABAURRE, M.L. et al. Português: língua e literatura. Volume único. São Paulo: Moderna, 2003.

AUFDERSTRAßE, H. Themen neu 2; Kursbuch. Berlin: Hueber, 2000.

AUFDERSTRAßE, H. Themen neu 2; Arbeitsbuch. Berlin: Hueber, 2000a.

BAGNO, M. Dramática da língua portuguesa; tradição gramatical, mídia e exclusão social. São Paulo: Loyola, 2001.

BASÍLIO, M. Introdução: questôes clássicas e recentes na delimitação de unidades lexicais. In: BASILIO, M. (Org.). A Delimitação de Unidades Lexicais. Palavra 5, Volume Temático I. Rio de Janeiro: PUC-RIO, 1999.

BASÍLIO, M. O conceito de vocábulo na obra de Mattoso Câmara. DELTA; Documentação de Estudos em Lingüística Teórica e Aplicada, v. 20, 2004.

BECHARA, E. Ensino da Gramática. Opressão? Liberdade? São Paulo: Ática, 1998.

BECHARA, E. Moderna Gramática Portuguesa. São Paulo: Nova Fronteira, 2010.

BLOOMFIELD, L. A set of postulates for the science of language. Language, v. 2, n. 3, Sep., 1926, p. 153-164.

BORGES, E. F. V. Metodologia, abordagem e pedagogias de ensino de língua(s). Linguagem e Ensino, Pelotas, v. 13, n. 2, 2010, p. 397-414.

BORNHEIM, G. A.. O conceito de tradição. In: et al. (Org.). Cultura brasileira: tradição/contradição. Rio de Janeiro: Jorge Zahar, 1987.

BUßMANN, H. Lexikon der Sprachwissenschaft. Stuttgart: Alfred Kröner Verlag, 1990.

BUßMANN, H. Routledge dictionary of language and linguistics. London/New York: Routledge, 1996.

CÂMARA Jr., J. Mattoso. Principios de Lingüistica Geral. Rio de Janeiro: Livraria Acadêmica, 1967.

CÂMARA Jr., J. Mattoso. Estrutura da língua portuguesa. Petrópolis: Vozes, 1986.

CEGALLA, D. P. Novíssima gramática da língua portuguesa. São Paulo: Cia. Editora Nacional, 1998.

CAGLIARI, L. Alfabetização e Linguística. São Paulo: Scipione, 1996.

CHOMSKY, N. Syntactic structures. Berlin/New York: de Gruyter, 2002.

CUNHA, C.; CINTRA, L. F. L. Nova gramática do português contemporâneo, 2. ed. Rio de Janeiro: Nova Fronteira, 1985. 
DACANAL, J. H. Linguagem, poder e ensino da língua. Porto Alegre: Mercado Aberto, 1987.

DELGADO LEÓN, F. Gramática clásica, gramática española, historia de la lingüística. Revista Española de Lingüística, 7, 2, 1977, p. 81-96.

DUDEN. Grammatik der deutschen Gegenwartssprache. DRODOWSKI, G. (Org.). Mannheim/Wien/Zürich: Bibliographisches Institut, 1998.

DUDEN. Grammatik der deutschen Gegenwartssprache. DRODOWSKI, G. (Org.). Mannheim/Wien/Zürich: Bibliographisches Institut, 1995.

DÜRSCHEID, C. Syntax; Grundlagen und Theorien. Göttingen: Vandenhoeck \& Ruprecht, 2007.

EISI, Ernst. Der Wortinhalt; Seine Struktur im Deutschen und Englischen. Heidelberg: Quelle und Meyer, 1995.

FIGUEIREDO, J. M. N.; FERREIRA, A. Gomes. Compêndio de gramática portuguesa. Porto: Porto Editora, 1979.

FLIEGNER, J. Grammatik verstehen und gebrauchen. Frankfurt/Main: Scriptor, 1986.

FUNK et al. studio d A1; Deutsch als Fremdsprache: Kurs- und Übungsbuch. Berlin: Cornelsen, 2005.

FUNK et al. studio d A2; Deutsch als Fremdsprache: Kurs- und Übungsbuch. Berlin: Cornelsen, 2008.

GONZÁLEZ CALVO, J. M. 'Las partes de la oración', una expresión engañosa. Anuario de Estudios Filologicos, V, Cáceres, 1982, p. 55-67.

HEIBIG, G.; BUSCHA, J. Deutsche Grammatik; Ein Handbuch für den Ausländerunterricht. Leipzig: Langenscheidt Verlag Enzyklopädie, 1996.

JOLIVET, R. Curso de Filosofia. Trad. Eduardo P. de Mendonça. São Paulo: Agir, 1984.

JOVANOVIC, A. Ensino de línguas e o papel da gramática. Revista da Faculdade de Educação (FE-USP), 12 (1/2), jan./dez. 1986, p. 145-156.

JUNG, L. Methodes des Fremdsprachenunterrichts.: 99 Stichwörter zum Unterricht Deutsch als Fremdsprache. Berlin: Hueber, 2000.

KUMARAVADIVELU, B. Understanding language teaching; from method to postmethod. Mahwah: Lawrence Erlbaum Associates, 2006.

KUMARAVADIVELU, B. TESOL methods: changing tasks; challenging trends. TESOL Quarterly, v. 40, n. 1, 2006a, p. 59-81. 
KUHN, T. S. Die struktur wissenschaftlicher Revolutionen. Frankfurt/Main: Suhrkamp, 1967.

LEITE, M. Q. Metalinguagem e discurso: a configuração do purismo brasileiro. São Paulo: Humanitas, 2006.

LEMCKE, C. et al. Berliner Platz A1; Deutsch im Alltag für Erwachsene. Lehr- und Arbeitsbuch. Berlin: Langenscheidt, 2005.

LUFT, C. P. Lingua e liberdade. São Paulo: Ática, 1987.

LYONS, J. Introduction to theoretical linguistics. New York: Cambridge University Press, 1968.

MOLINO, J. Saussure et l'économie. Revue europeenne des ciences sociales, XX, n. 66. Genève: Librairie Droz, 1984, p. 145-162.

NEUNER et al. Deutsch aktiv neu 1; Kursbuch. Berlin: Langenscheidt, 1988.

NEVES, M. H. M. Que gramática estudar na escola? Norma e uso da Língua Portuguesa. São Paulo: Contexto, 2002.

PERCIVAL, W. K. On the Historical Source of Immediate-Constituent Analysis. In: McCAWLEY, D. (Org.). Notes from the Linguistic Underground, Syntax and Semantics, vol. 7. New York: Academic Press, p. 229-242, 1976.

PERINI, M. A. Gramática descritiva do português. São Paulo: Ática, 1995.

PERINI, M. A. Para uma nova gramática do Português. São Paulo: Ática, 2000.

POSSENTI, S. Por que (não) ensinar gramática na escola? Campinas: Mercado de Letras, 1996.

RASTER, P. Der Ursprung der Grammatik in Indien und Europa und die Achsenzeit der Weltgeschichte. In: YOUSEFI, H. R.; FISCHER , K. (Org.). Interkulturalität: Diskussionsfelder eines umfassenden Begriffs. Nordhausen: Bautz, 2010. p. 287-309.

ROCHA, L. C. A. Gramática nunca mais; o ensino da língua padrão sem o estudo da gramática. São Paulo: Martins Fontes, 2002.

RUWET, N. Introdução à gramática gerativa. São Paulo: Perspectiva, 1975.

SAUSSURE, F. Cours de linguistique générale. Paris: Payot, 1967.

SCHUNK, G. Studienbuch zur Einführung in die deutsche Sprachwissenschaft; Vom Laut zum Wort. Würzburg: Königshausen und Neumann, 1997.

SILVA, G. A. A era pós-método: o professor como um intelectual. Revista Linguagens e Cidadania, n. 12, 12/04, 2008. Santa Maria: UFSM. 
SMYTH, H. W. Greek Grammar. Cambridge: Harvard University Press, 1956.

SUASSUNA, L. Ensino de língua portuguesa; uma abordagem pragmática. Campinas: Papirus, 2002.

TAVAGLIA, L. C. Gramática e interação; uma proposta para o ensino de gramática no 1o. e 2o. graus. São Paulo: Cortez, 2001.

TWADDELL, W. F. The study of syntax: past, present and future. In: Essays in honor of Charles F. Hockett. Leiden: E. J. Brill, 1983. p. 35-48.

WELSCH, W. Mudança estrutural nas ciências humanas: diagnóstico e sugestões. Revista Educação, n. 2 (62), maio/ago. 2007. Porto Alegre: PUC-RS, p. 237-258. 